Article

\title{
Cost-Effectiveness Analysis of the Use of Point-of-Care C-Reactive Protein Testing to Reduce Antibiotic Prescribing in Primary Care
}

\author{
Emily A. F. Holmes ${ }^{1} * *^{\mathbb{D}}$, Sharman D. Harris ${ }^{2}$, Alison Hughes ${ }^{3}$, Noel Craine ${ }^{4}$ and \\ Dyfrig A. Hughes ${ }^{1}$ \\ 1 Centre for Health Economics and Medicines Evaluation (CHEME), Bangor University, Normal Site, \\ Bangor, Gwynedd LL57 2PZ, UK; d.a.hughes@bangor.ac.uk \\ 2 Department of Blood Sciences, Betsi Cadwaladr University Health Board, Ysbyty Gwynedd LL57 2PW, UK; \\ Sharman.D.Harris@wales.nhs.uk \\ 3 Head of Pharmacy Primary Care and Community West, Betsi Cadwaladr University Health Board, \\ Pharmacy Office, Eryldon, Campbell Rd, Caernarfon, Gwynedd LL55 1HU, UK, \\ Alison.Hughes9@wales.nhs.uk \\ 4 Public Health Wales, Microbiology Department, Ysbyty Gwynedd, Bangor, Gwynedd LL57 2PW, UK; \\ Noel.Craine@wales.nhs.uk \\ * Correspondence: e.holmes@bangor.ac.uk; Tel.: +44-1248-382-709
}

Received: 19 October 2018; Accepted: 3 December 2018; Published: 7 December 2018

\begin{abstract}
More appropriate and measured use of antibiotics may be achieved using point-of-care (POC) C-reactive protein (CRP) testing, but there is limited evidence of cost-effectiveness in routine practice. A decision analytic model was developed to estimate the cost-effectiveness of testing, compared with standard care, in adults presenting in primary care with symptoms of acute respiratory tract infection (ARTI). Analyses considered (1) pragmatic use of testing, reflective of routine clinical practice, and (2) testing according to clinical guidelines. Threshold and scenario analysis were performed to identify cost-effective scenarios. In patients with symptoms of ARTI and based on routine practice, the incremental cost-effectiveness ratios of CRP testing were $£ 19,705$ per quality-adjusted-life-year (QALY) gained and $£ 16.07$ per antibiotic prescription avoided. Following clinical guideline, CRP testing in patients with lower respiratory tract infections (LRTIs) cost $£ 4390$ per QALY gained and $£ 9.31$ per antibiotic prescription avoided. At a threshold of $£ 20,000$ per QALY, the probabilities of POC CRP testing being cost-effective were 0.49 (ARTI) and 0.84 (LRTI). POC CRP testing as implemented in routine practice is appreciably less cost-effective than when adhering to clinical guidelines. The implications for antibiotic resistance and Clostridium difficile infection warrant further investigation.
\end{abstract}

Keywords: economic evaluation; cost-utility analysis; cost-effectiveness analysis; antibiotics; primary care; respiratory tract infection; point-of-care testing; C-reactive protein; antimicrobial resistance; Clostridium difficile

\section{Introduction}

Respiratory tract infections (RTI) are the most common presenting complaint in primary care and the most common reason for antibiotic prescribing in Europe [1]. Whilst antibiotics will benefit lower respiratory tract infections (LRTI) of bacterial origin, they are often prescribed inappropriately, such as for viral upper RTI, putting patients at risk of adverse effects with limited or no therapeutic benefit [2]. Identifying patients presenting with bacterial LRTI that require an antibiotic represents a challenge to healthcare professionals. Unnecessary antibiotic prescribing also increases the risk of development of 
antimicrobial resistance [2-5] and Clostridium difficile infection [6]. The vital importance of addressing antimicrobial resistance at a local, national and international level is widely recognized [7]. O'Neill's report for the United Kingdom (U.K.) government [8], the National Institute of Health and Care Excellence (NICE) guidelines on antimicrobial stewardship [9], and the Welsh Government delivery plan for Wales "Tackling antimicrobial resistance and improving antibiotic prescribing" [10], all highlight the urgency of the task.

To avoid unnecessary use of antibiotics, the NICE advises considering point-of care (POC) C-reactive protein (CRP) testing in primary care in patients presenting with symptoms of LRTI, when clinical assessment is not conclusive and it is not clear whether antibiotics should be prescribed [11]. The clinical guideline recommends that antibiotic therapy should not be routinely offered if the CRP is $<20 \mathrm{mg} / \mathrm{L}$; a delayed antibiotic prescription should be considered if the CRP is $20-100 \mathrm{mg} / \mathrm{L}$; and antibiotic therapy should be offered if the CRP is $>100 \mathrm{mg} / \mathrm{L}$ [11].

In Wales, the national policy is for wider use of POC CRP testing as a prognostic tool in primary care to aid clinical decisions about the appropriateness of antibiotic prescribing [12]. Implementation of POC CRP testing across Wales requires a clear understanding of the potential costs and benefits associated with its use. A meta-analysis including 10,005 patients showed that CRP testing was associated with a significant reduction in antibiotic prescribing at index consultation but not at 28-day follow-up, and did not impact on patient satisfaction [13]. A more recent review [14] suggested that reductions in antibiotic prescribing attributable to POC CRP testing range from $23 \%$ to $36 \%$ [15-19]. Economic evaluations of POC CRP testing in managing RTIs suggest potential cost savings [20-23]; however, these are of variable quality and based on key assumptions concerning the effectiveness of implementation of POC CRP testing, laboratory support costs, and connectivity to wider healthcare systems [24]. A formal analysis of the cost-effectiveness of CRP testing in patients presenting with acute respiratory tract infection (ARTI) in the context of routine National Health Service (NHS) primary care service delivery, which considers the full costs of implementation, is therefore required. Given the objective of POC CRP testing is to reduce unnecessary antibiotic prescribing, in order to conserve the effectiveness of current antimicrobials, economic evaluations of POC CRP testing have the added challenge of how best to capture the cost of antimicrobial resistance [25].

The aim of the economic evaluation was to estimate the cost-effectiveness of POC CRP testing of adult patients presenting with symptoms of ARTI in routine use, acknowledging widespread non-compliance with clinical guidelines, and to compare this with the cost-effectiveness of testing according to clinical protocol. The study design is an economic model based on empirical data from a published study [26]. This is the first study, to our knowledge, to consider the influence on the cost-effectiveness of POC CRP testing of deviations from clinical guidelines-such as prescribing antibiotics regardless of test result-that are common occurrences in routine practice. Evidence generated by this evaluation suggests pragmatic use of POC CRP testing is considerably less cost-effective than when adhering to clinical guidelines, and that including the cost of antimicrobial resistance in the model improves the cost-effectiveness of POC CRP testing.

\section{Results}

\subsection{Base Case Analysis}

The study population had a median age of 48.5 years, and $69 \%$ were female (one participant out of 71 was lost to follow-up and was excluded from the analysis) [26]. The mean number of CRP tests received over 28 days was 1.03 per patient, at a cost of $£ 9.85$ (95\% confidence interval [CI] 9.63 to 10.42). With POC CRP testing 18/70 patients received antibiotics (Table 1). At least 10 of these prescriptions would be considered unnecessary according to CRP testing guidelines (143/1000 prescriptions). Compared with standard care, the modelled incremental cost of the POC CRP strategy in the ARTI population, was $£ 11.92$ (95\% CI 9.35 to 15.39); the main cost drivers were the costs of the test and re-consultation. Modelled differences in quality-adjusted-life-years (QALYs) between standard care and POC CRP were 0.0006 (95\% 
CI -0.0006 to 0.0019 ), which is equivalent to approximately five additional hours of perfect health over 28 days. The base-case incremental cost-effectiveness ratio (ICER) is therefore $£ 19,705$ per QALY gained. The cost-effectiveness of POC CRP testing for ARTI is estimated to be $£ 16.07$ per antibiotic prescription avoided ( $£ 11.25$ per $1 \%$ reduction in antibiotic prescribing).

Table 1. Cost-effectiveness of point-of-care (POC) C-reactive protein (CRP) testing for adults with symptoms of acute respiratory tract infection (ARTI) for $>12 \mathrm{~h}$ where the antibiotic decision is unclear versus immediate antibiotic prescription. CI: Confidence Interval; ICER: Incremental cost-effectiveness ratio.

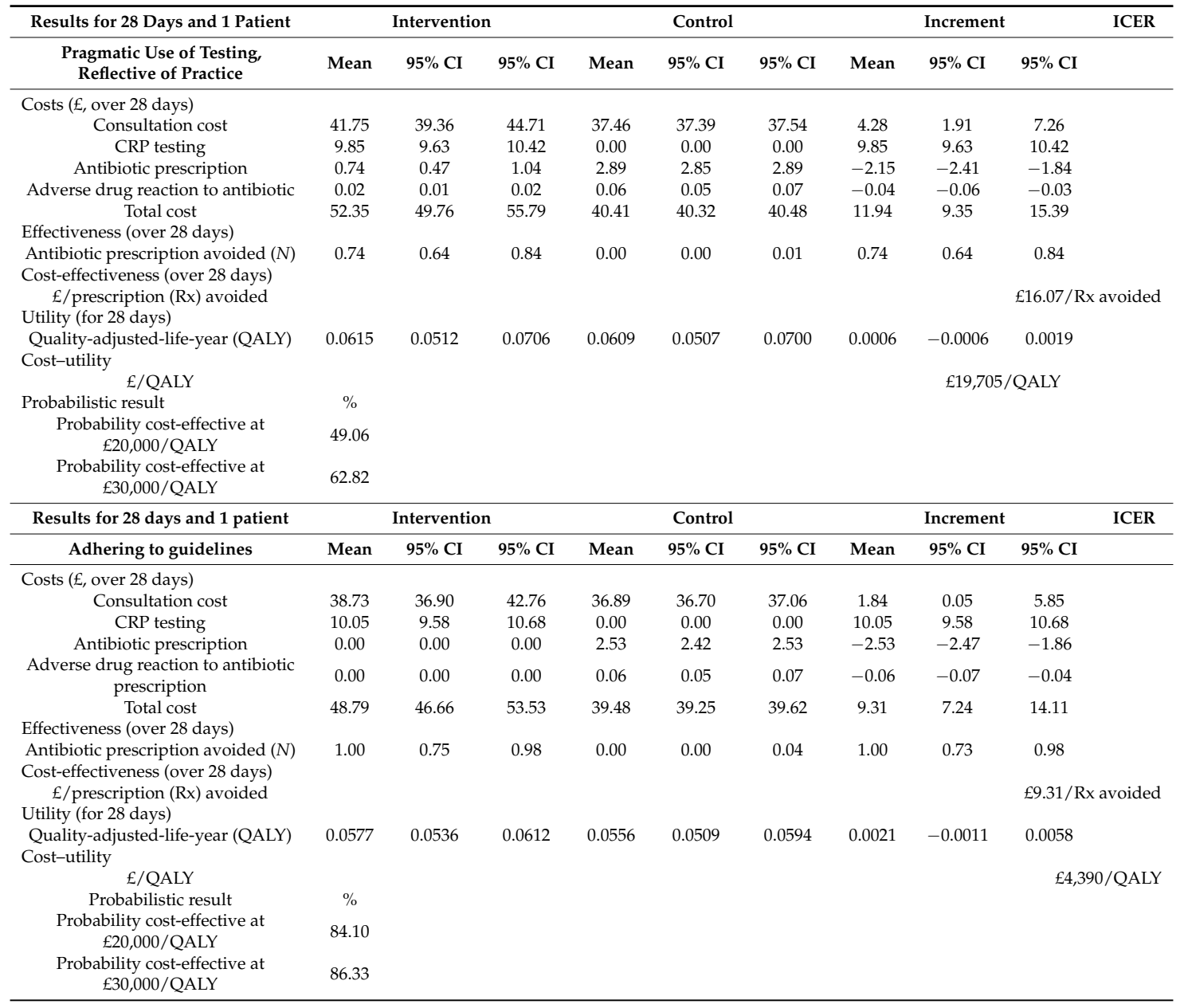

\subsection{Sensitivity and Scenario Analyes}

\subsubsection{One-Way Sensitivity and Threshold Analyses}

The threshold analysis revealed that if each POC CRP test were 18 pence more expensive, the ICER would exceed $£ 20,000$ per QALY gained (Table 2). If CRP test usage were to fall by $5 \%$ (from 37 to 35 tests $/ 1000$ patient-years) the ICER for ARTI will exceed $£ 20,000$ per QALY. Adjusting the proportion of patients seen by a general practitioner (GP) or independent nurse prescriber (INP) consultation varied the ICER from $£ 16,288$ to $£ 19,749$ per QALY. 
Table 2. Results of sensitivity and scenario analyses.

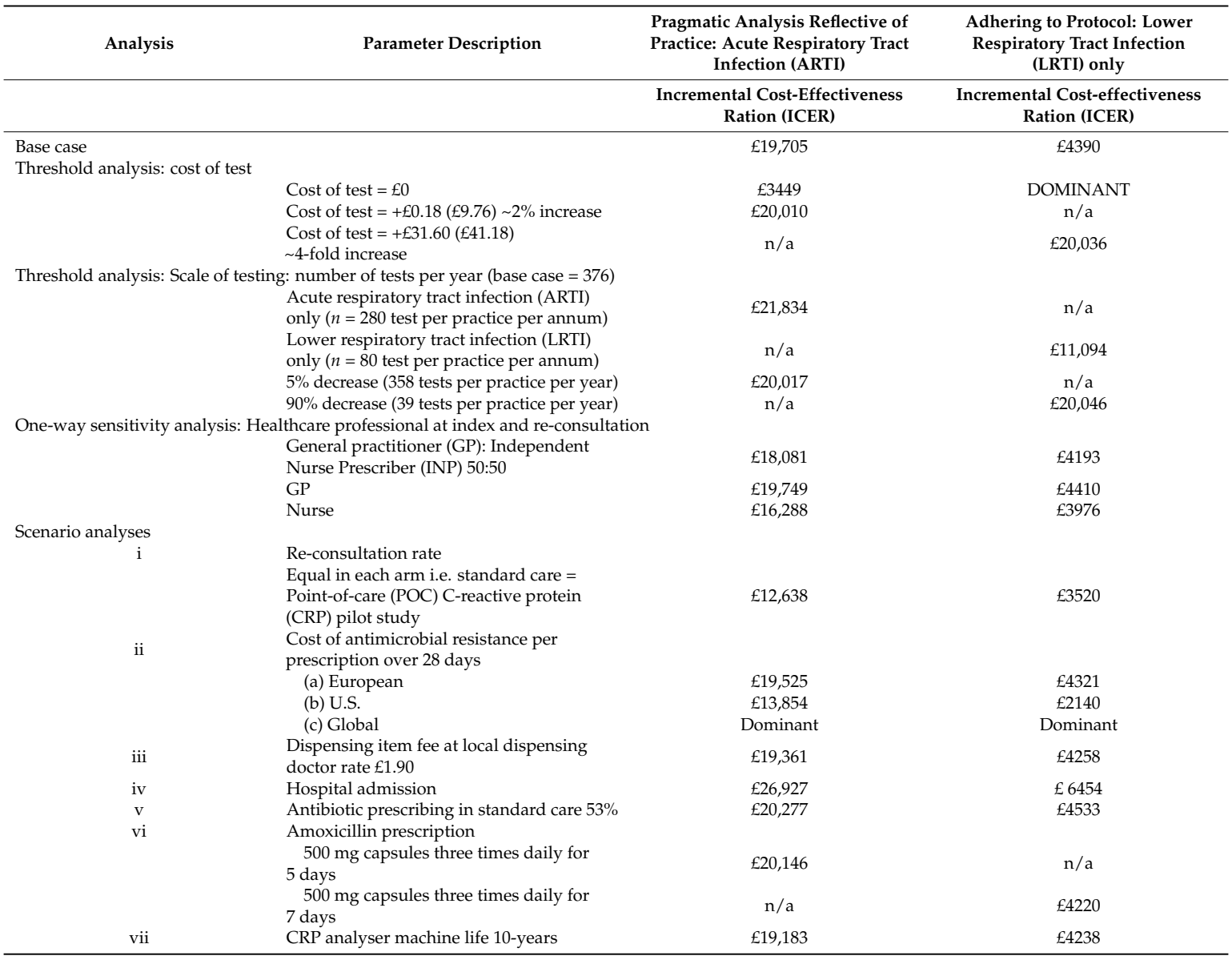

\subsubsection{Probabilistic Sensitivity Analysis}

The cost-effectiveness plane for the ARTI base case analysis is illustrated in Figure 1. The distribution of the simulations indicates that POC CRP testing results in higher utility (health gain) but at higher cost in $75 \%$ of simulations. The corresponding cost-effectiveness acceptability curve (CEAC) indicates the probabilities of POC CRP testing for ARTI being cost-effective were 0.49 and 0.63 at the $£ 20,000$ and $£ 30,000$ per QALY thresholds, respectively (Figure 2).

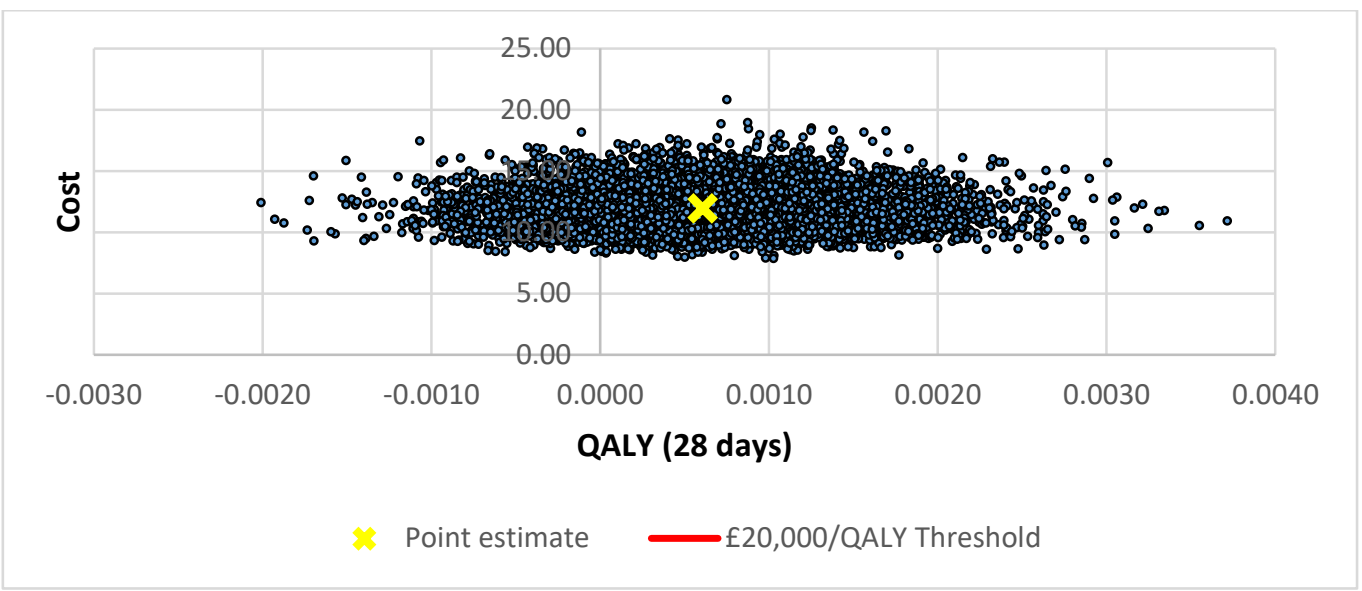

Figure 1. Cost-effectiveness plane for pragmatic use of POC CRP testing. 


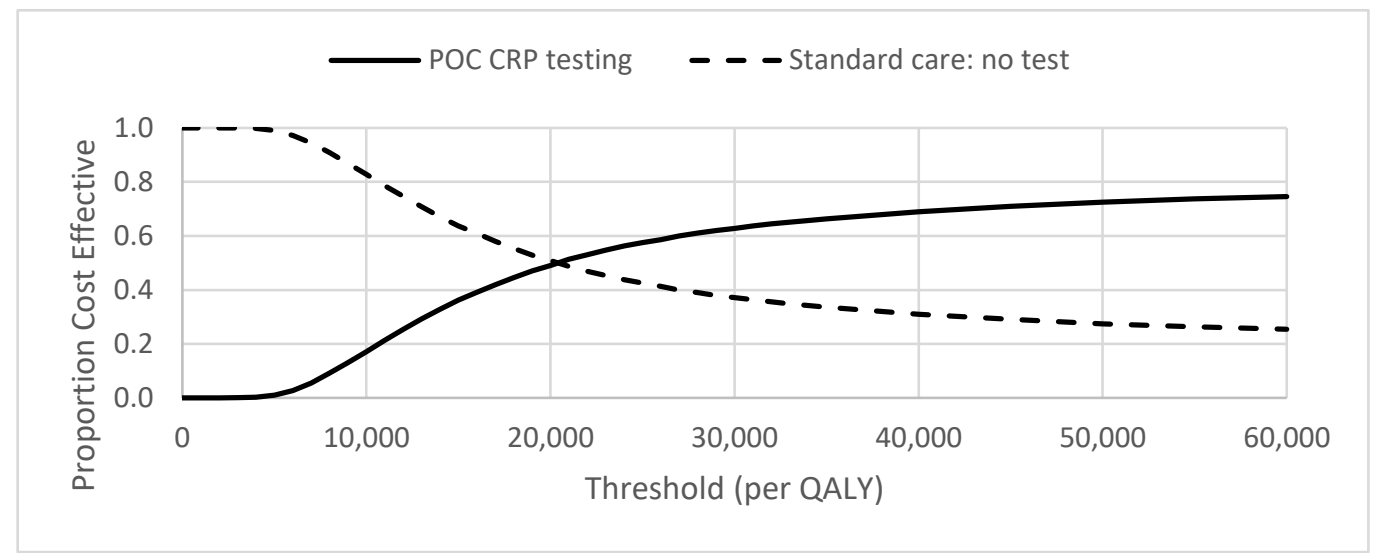

Figure 2. Cost-effectiveness acceptability curve (CEAC) for pragmatic use of POC CRP testing.

\subsubsection{Scenario Analyses}

The scenario of restricting CRP testing to patients with symptoms of LRTI for $>12 \mathrm{~h}$; is represented by a sub-group of 20 patients with a median age 48.5 years, $55 \%$ female. Based on the observed CRP test results for the study population (no CRP $>100 \mathrm{mg} / \mathrm{L}$ ) [26], the model predicts a 100\% reduction in antibiotic prescribing at an incremental cost of $£ 9.31$ per patient (95\% CI 7.24 to 14.11) (Table 1). The increase in total cost is attributable to the cost of POC CRP testing ( $£ 10.05$ per patient), which is not outweighed by the savings in antibiotic prescribing costs ( $-£ 2.53$ per patient). The cost-utility analysis indicates that POC CRP testing for LRTI, according to protocol, is associated with a 0.0021 QALY gain (95\% CI -0.0011 to 0.0058 ), equivalent to about 19 quality-adjusted hours, with a resulting ICER of $£ 4390$ per QALY gained. There is capacity for test prices to increase 4-fold before the ICER reaches the $£ 20,000$ per QALY threshold. Probabilistic sensitivity analysis for this scenario indicates that POC CRP testing is associated with increased QALYs and higher cost in $88 \%$ of simulations and a probability of being cost-effective at a threshold of $£ 20,000$ per QALY threshold, of 0.84 .

Additional scenarios indicate that the ICER decreases (i) under the assumption of equal re-consultation rates for both standard care and CRP testing, regardless of antibiotic prescribing; (ii,a\&b) when accounting for antimicrobial resistance; (iii) when a 7-day course of amoxicillin is dispensed by a doctor; and (vii) if the machine-life is extended to 10-years. POC CRP testing is dominant when (ii,c) the cost of each antibiotic prescription includes the global cost of treating antimicrobial resistance [27]. POC CRP testing is less cost-effective (higher ICER) when the model includes (iv) hospitalizations related to ARTI; or (v) a lower rate of antibiotic prescribing in standard care (53\%) reduces the cost-effectiveness (increases the ICER). Testing is no longer cost-effective if (vi) prescribing guidelines are adhered to (5-day instead of 7-day course of amoxicillin).

\section{Discussion}

\subsection{Key Findings}

The model suggests that as implemented in routine primary care (for all adults with symptoms of ARTI for $>12$ hours where the antibiotic decision unclear) POC CRP testing is borderline cost-effective [28]. There are a number plausible scenarios where testing outside the recommendations of the NICE clinical guideline exceeds the cost-effectiveness threshold. Closer adherence to the NICE CRP recommendation, however, by restricting testing to adults with symptoms of LRTI, and prescribing appropriate courses of antibiotics, results in a more favourable ICER. The main cost driver is the cost of a CRP test which, for ARTI must be below $£ 9.76$ per test to be considered cost-effective. This represents a small increase $(+£ 0.18)$ from the current estimate, that may easily be caused by changes in unit costs or throughput (such as a $5 \%$ increase in agent costs, $£ 6 /$ month increase in laboratory support costs, $17 \%$ increase in equipment costs, or $5 \%$ reduction in the use of testing). 
Including the cost of antimicrobial resistance in the model improves the cost-effectiveness of POC CRP testing, but there are uncertainties associated with specifying this cost, and resistance would also affect the efficacy of the antibiotic, which was not explicitly considered in this analysis. This evaluation did, however, identify a $74 \%$ absolute reduction in antibiotic prescribing (from 70 to 18 prescriptions) and an $89 \%$ reduction in unnecessary prescribing for adults with ARTI. It is plausible that reductions in unnecessary prescribing could conserve the effectiveness of current antimicrobials.

\subsection{Comparisons to Other Studies}

We are aware of four published economic evaluations of POC CRP testing for RTI. Cals et al. (2011) conducted a cost-effectiveness analysis of POC CRP testing by GP versus standard care based on data from a cluster randomised factorial clinical trial of 431 patients with LRTIs recruited in 40 GP practices [20]. They reported an ICER of $€ 5.79$ per $1 \%$ reduction in antibiotic prescribing (corresponding to $£ 4.02$ ). Oppong et al., (2013) conducted an economic evaluation based on an observational study of the presentation, management, and outcomes of patients with acute cough and LRTI in primary care settings in Norway and Sweden, and reported an ICER of $€ 9,391$ per QALY gained [23]. NICE based their analysis on the incremental QALY (0.0012) reported by Oppong et al. (2013) [23] to estimate an ICER of $£ 15,763$ per QALY gained [11]. This included the cost of hospitalization, as evaluated in our scenario analysis. More recently, Hunter (2015) conducted an analysis which included both hospitalizations and the costs of complications of antibiotic prescribing, and reported CRP testing dominates current practice [22].

Studies of POC CRP testing are characterized by uncertainty that may be attributable to valuation of the test, heterogeneity in study population, and the subjectivity of the indication. Regents were $75 \%$ of costs in the analysis by Cals et al. (2011) [20], but accounted for only 37\% the current analysis. The proportion of cost attributable to reagent was similar in the analysis by Hunter (2015) [22], however, costs were limited to reagent, depreciation and staff time. Other studies provide no details of what was included in the valuation [11,23]. Furthermore, defining the eligible patient population requires a subjective judgement, i.e. "where the antibiotic decision is unclear", that represents a challenge for economic modelling. By considering the use of testing as routinely implemented in practice, our analysis reflects the judgements of GPs.

\subsection{Strengths}

To our knowledge, this is the first study in the UK to model the cost-effectiveness of POC CRP testing using data from use in routine clinical practice, and to include support costs for the management of POC testing in primary care. The probabilities in the model were based on individual patient-level data, undertaken over 3 months, in a GP surgery that had a high rate of antibiotic prescribing. The analysis, therefore, reflected the real world situation of protocol deviations and provides an estimate of the cost-effectiveness (as opposed to the cost-efficacy) of testing. Unlike previous studies, our analyses also attempted to incorporate the long-term cost implications of antimicrobial resistance.

\subsection{Limitations}

The time horizon of the model is unable to assess the longer-term effects of unnecessary antibiotic prescribing, such as the increased antibiotic resistance and increased risk of Clostridium difficile infection [5,29]. The scenario analysis of antibiotic resistance is limited to a projected cost and is not reflective of patients' health-related quality of life. The utilities associated with RTI are baseline estimates and the model assumes this is constant for the duration of the illness; due to a lack of disaggregated longitudinal data. The disutility of common adverse events, such as diarrhoea, are assumed to be captured by time to full recovery, which may underestimate resource use and overestimate utility associated with antibiotic prescribing. Finally, this model is representative of outlying practice. The estimate of $100 \%$ prescribing of antibiotics in standard care, and non-compliance to POC CRP guidelines, is less likely in other places. 


\subsection{Implications}

This analysis highlights the reduction in cost-effectiveness attributable to protocol deviation, as is expected in a routine clinical setting. The cost-effectiveness of the POC CRP testing strategy is highly sensitive to the cost of the test, therefore when interpreting the result in other settings; consideration should be given to test cost drivers, such as machine throughput. Economies of scale are likely to be limited by the size of the practice population and uptake of the test by healthcare professionals.

\subsection{Future Research Directions}

Further research is required to capture the effects of antimicrobial resistance and increased risk of Clostridium difficile infection, both of which are associated with increased NHS costs [27,29], morbidity and mortality; and have long term impacts on health-related quality of life and society $[25,29]$. The appropriateness of QALYs for use in evaluation of acute conditions, such as respiratory tract infections, warrants further exploration; alternative methods such as willingness to pay have been suggested [30]. Beyond the testing strategy, research is also required on behavioural aspects, such as protocol adherence by healthcare professionals and the influence on the test on medication adherence by the patients.

How best to assess the value of any intervention to reduce antimicrobial resistance is a methodological challenge, which requires adequate measurement of the expected rate of growth of antimicrobial resistance and associated outcomes over time [31]. Rothery and colleagues [31] recently outlined a framework for value assessment of new antimicrobials that uses modelling to estimate infection transmission dynamics, associated resistance, and economic outcomes, for alternative treatment strategies. The report highlights several implications for health technology assessment [31]. Modelling infection transmission dynamics and resistance outcomes over time is complex and relies on the multidisciplinary teams (mathematical modellers, epidemiologist, data experts, clinical experts, and health economists). There is greater reliance on observational data and dynamic transition modelling rather than cohort statistic modelling. This is associated with more extensive and systematic use of expert elicitation methods; and, of model calibration for interring values for unobservable parameters or limited efficacy data. Furthermore, there are difficulties in measuring and valuing health-with limited data on utility values, difficulty measuring health related quality of life in short severe infections, and difficulty measuring the disutility and costs of onward transmission of infections to the wider population. Typical health technology appraisal, such as that conducted by NICE, is based on the "average" patient receiving a treatment for a specified indication. When considering the consequences of antibiotic prescribing benefits and costs extend to a wider population, within which diversity in settings (e.g., community care, intensive care) will influence the spread of infections in the population. Given this extension to the population level, Rothery and colleagues, also highlight the issue of an indefinite time horizon [31]. Future research therefore needs to address the challenge of how to formally characterize the value of interventions with the potential to reduce antimicrobial resistance and to measure the opportunity cost used to guide this longer term and more global decision. Rothery and colleagues suggest the following uncertainties need to be considered: prevalence of infections, resistance patterns over time, stock of future antibiotics, lag periods before resistance, irreversible impacts. A broader perspective may also be necessary, to explore issues such as the insurance value of avoiding major health consequences if antimicrobial resistance becomes substantially worse [25], and antibiotic use in farming with associated events, for example, standards relating to the import of diary and meat into the United Kingdom and associated trade deals on departure from the European Union [32].

\section{Materials and Methods}

We conducted a cost-effectiveness analysis of antibiotic prescribing conditional on POC CRP testing for adults presenting in primary care (GP practice) with symptoms of ARTI for $>12 \mathrm{~h}$ versus 
immediate antibiotic prescription (current standard of care). The analysis had a 28-day time horizon, conducted from the perspective of the NHS in the United Kingdom.

\subsection{Economic Model}

A decision analytic model was developed with a time horizon of 28 days from the index consultation (Figure 3). The model was structured to represent the following care pathways [11]: (1) standard care, in which patients receive no test (as per current practice) and instead receive an antibiotic prescription for immediate use, and (2) a strategy of testing for CRP, where patients have three potential prescription outcomes, no antibiotic prescribed, antibiotic prescribed for immediate use, or for delayed use [33]. Patients who are offered a delayed prescription are offered a prescription for use at a later date if symptoms worsen. The model accounts for whether or not a delayed prescription, issued at the index consultation (based on CRP 20-100 mg/L), is dispensed.

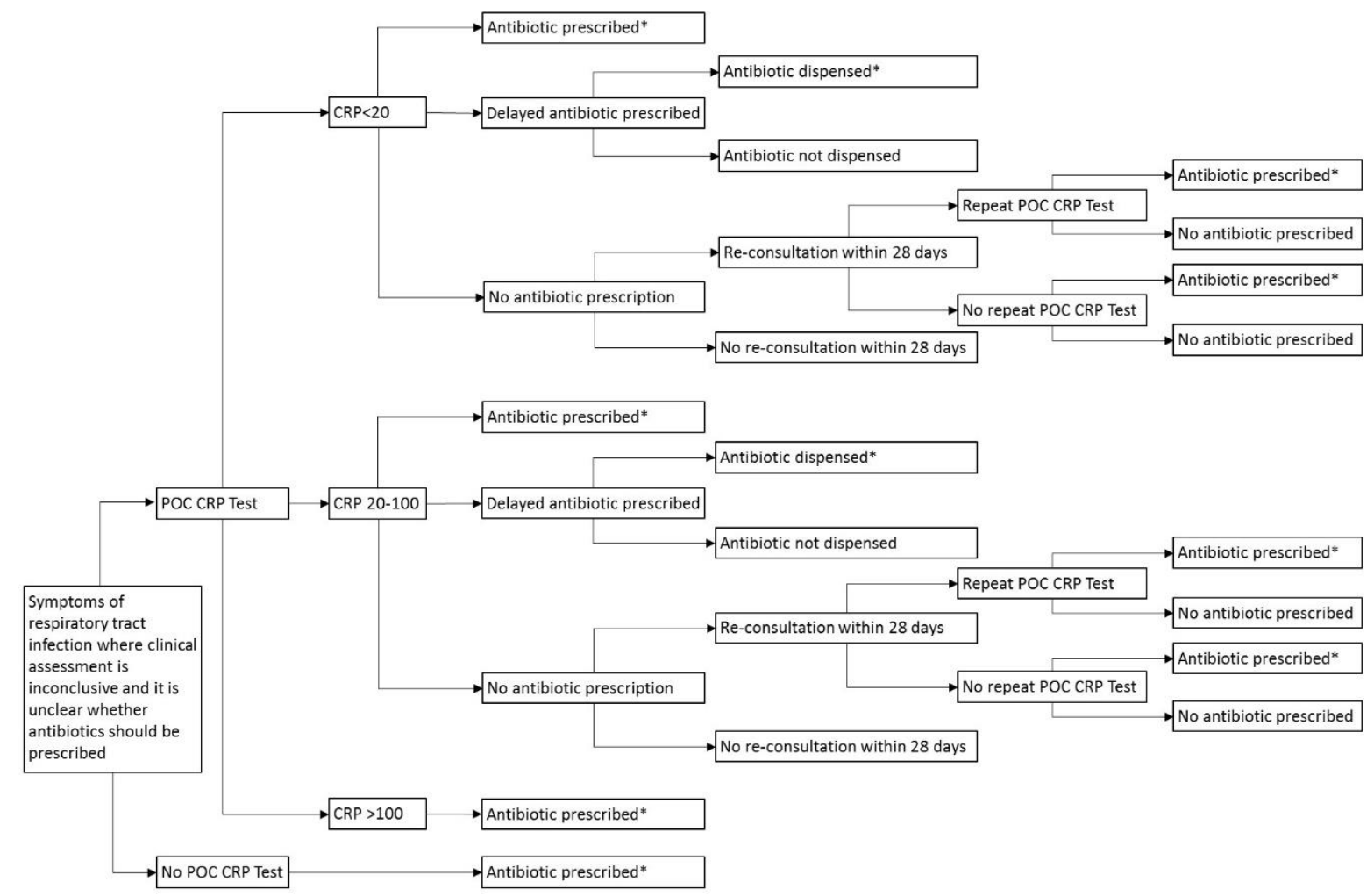

Figure 3. Decision tree for pragmatic use of POC CRP testing, reflective of practice. POC: Point-of-care; CRP: C-reactive protein; *Amoxicillin $500 \mathrm{mg}$ three times daily for 7 days.

The model also takes account of re-consultations occurring within 28 days where patients on the CRP testing pathway receive no antibiotic prescriptions (CRP $<20 \mathrm{mg} / \mathrm{L}$ ). At re-consultation, the model considers whether or not patients receive a repeat CRP test and thereafter, whether antibiotics are prescribed or not. Patients who were not going to receive an antibiotic prescription irrespective of testing did not enter the model.

\subsubsection{Clinical Parameters}

The model was parameterized using data from purposive reviews of the literature, in line with standard methodology for populating economic models [34]. These supplemented data from a published study [26] undertaken in a general practice surgery that serves 10,200 patients in Anglesey, North Wales, UK. The practice was in the top one percentile in England and Wales for antibiotic prescribing [35]. A POC CRP analyser was introduced in November 2015 and used for 3 months, based on the NICE clinical guideline for pneumonia [11]. POC testing was supported by a laboratory POC 
team as specified by national policy [12]. Within the study [26], data were collected on POC CRP test results, antibiotic decision, re-consultation within 28 days for the same complaint, and, the outcome of any decision to prescribe antibiotics at any re-consultation. Dispensing of delayed prescriptions within 28 days of the index consultation was determined by retrospective review of the online NHS Wales Shared Services "primary care prescribing catalogue" [36]. Patients who were lost to follow-up were excluded from the analysis. Clinical parameter estimates (probabilities) are listed in Table 3.

The standard care arm of the economic model is based on routine clinical practice at the same location. We assumed that $100 \%$ of patients (adults with symptoms of ARTI for 12 or more hours where the antibiotic decision is unclear) in the standard care arm of the model received an immediate prescription. Re-consultation rates in the standard care arm were modelled on the rate of re-consultation in the CRP pilot study for patients who received antibiotics at index consultation $(0 \%$ at 28 days; [26].

All patients in the model had a risk of hypersensitivity reaction to antibiotic therapy that is independent of CRP testing strategy or re-consultation rates. As there were no recorded cases of adverse drug reactions in the pilot study, the probability of anaphylaxis was taken as that for amoxicillin, and assumed to be 1 in 10,000 people [37].

\subsubsection{Resource Use and Costs}

Resource use included GP or INP index and re-consultation, CRP testing, antibiotic prescription and treatment of adverse drug reactions. The rate of index consultation and subsequent consultations, and the proportion of patients who consulted with a GP or INP, face-to-face or by telephone, was taken from Hughes et al., (2016) [26] and assumed to be the same for CRP testing as for standard care. Re-consultation with the same complaint occurred in 7/50 cases with upper respiratory tract infection (URTI) and 1/20 cases with LRTI. The cost of a consultation was based on a mean duration of $9.22 \mathrm{~min}$ with a GP [38] and assumed to be 15 min with an INP (Table 3). Costs of GP and nurse-led telephone triage were based on national figures [39].

Antibiotic prescriptions were assumed to be amoxicillin 500-mg capsules three times daily for 7 days, informed by retrospective review of prescribing at the GP practice involved in the study, where there were no records of a 5-day course being prescribed (as recommended). Local prescribing data showed that in this primary care cluster, $22 \%$ of amoxicillin prescriptions (all indications) were prescribed for 5 days. Prescription costs were taken from the British National Formulary at the Drug Tariff price [40]. An additional dispensing fee was included for every dispensed prescription, based on the mean dispensing rate per item for community pharmacists at the location [41].

The cost of a managing an anaphylaxis reaction (adverse drug reaction) consisted of ambulance treatment and transport, followed by emergency medicine investigation and treatment [41,42]. The model assumed all patients who experience a hypersensitivity reaction survive and are prescribed clarithromycin as an alternative antibiotic.

The cost of CRP testing included the cost of performing a test using the Alere Afinion AS100 analyser (Alere; MA, United States) (Table 4). This included the fixed cost of purchasing the analyser and variable costs of its use in clinical practice. Variable costs included consumables, internal quality control (IQC), external quality assurance (EQA), maintenance costs, connectivity, and hospital-based laboratory POC testing team assistance. Extra equipment was required to connect the analyser into the All Wales Laboratory Information System (LIMS), with the added cost of a company to connect the analyser so that results can be viewed in the patient record. The cost per test was calculated assuming a machine life of 5 years, based on the manufactures estimate, and the projected annual number of tests based on the number of test performed in 3 months [26]. In the base-case analysis, the test was assumed to be performed by a health care assistant (HCA), in addition to the standard consultation with GP/INP. 
Table 3. Model input parameters: probabilities, costs and utilities.

\begin{tabular}{|c|c|c|c|}
\hline Parameter & Point Estimate & Distribution $^{1}$ & References \\
\hline \multicolumn{4}{|c|}{ Probabilities } \\
\hline Antibiotics at index | C-reactive protein $(\mathrm{CRP})>100 \mathrm{mg} / \mathrm{L}$ & 1.00 & Fixed & [11] \\
\hline Antibiotics at index consultation I no CRP & 1.00 & Fixed & Assumption ${ }^{2}$ \\
\hline Anaphylactic reaction to antibiotic prescription & 0.0001 & Beta $(1,10,000)$ & [37] \\
\hline \multicolumn{4}{|c|}{ ARTI Observed Data } \\
\hline $\mathrm{CRP}<20 \mathrm{mg} / \mathrm{L}$ & 0.77 & Dirichlet $(54,16,0)$ & [26] \\
\hline CRP $20-100 \mathrm{mg} / \mathrm{L}$ & 0.23 & Dirichlet $(16,54,0)$ & [26] \\
\hline No antibiotics at index consultation $\mid \mathrm{CRP}<20 \mathrm{mg} / \mathrm{L}$ & 0.93 & Dirichlet $(50,2,2)$ & [26] \\
\hline Delayed prescription at index consultation I CRP $<20 \mathrm{mg} / \mathrm{L}$ & 0.04 & Dirichlet $(2,50,2)$ & [26] \\
\hline $\begin{array}{l}\text { Delayed prescription at index consultation not dispensed I } \\
\qquad \mathrm{CRP}<20 \mathrm{mg} / \mathrm{L}\end{array}$ & 1.00 & Beta $(1,0)$ & [26] \\
\hline Antibiotics at index consultation I CRP $<20 \mathrm{mg} / \mathrm{L}$ & 0.04 & Dirichlet $(2,50,2)$ & [26] \\
\hline No antibiotics at index consultation I CRP $20-100 \mathrm{mg} / \mathrm{L}$ & 0.38 & Dirichlet $(6,10,0)$ & [26] \\
\hline Antibiotics at index consultation I CRP $20-100 \mathrm{mg} / \mathrm{L}$ & 0.63 & Dirichlet $(10,6,0)$ & [26] \\
\hline No re-consultation within 28 days $\mid \mathrm{CRP}<20 \mathrm{mg} / \mathrm{L}$ & 0.86 & Beta $(43,7)$ & [26] \\
\hline No re-consultation within 28 days I CRP $20-100 \mathrm{mg} / \mathrm{L}$ & 0.83 & Beta $(5,1)$ & [26] \\
\hline No repeat CRP at re-consultation I CRP $<20 \mathrm{mg} / \mathrm{L}$ & 0.71 & Beta $(5,2)$ & {$[26]$} \\
\hline No repeat CRP at re-consultation I CRP $20-100 \mathrm{mg} / \mathrm{L}$ & 1.00 & Beta $(1,0)$ & {$[26]$} \\
\hline $\begin{array}{l}\text { CRP guided no antibiotic decision at re-consultation | CRP } \\
\qquad 20 \mathrm{mg} / \mathrm{L}\end{array}$ & 1.00 & Beta $(2,0)$ & [26] \\
\hline $\begin{array}{c}\text { Antibiotics at re-consultation I CRP }<20 \mathrm{mg} / \mathrm{L} \text { at index, CRP } \\
\text { not repeated at re-consultation }\end{array}$ & 1.00 & Beta $(5,0)$ & [26] \\
\hline $\begin{array}{l}\text { Antibiotics at re-consultation I CRP } 20-100 \mathrm{mg} / \mathrm{L} \text { at index, no } \\
\text { delayed prescription, CRP not repeated at re-consultation }\end{array}$ & 1.00 & Beta $(1,0)$ & [26] \\
\hline \multicolumn{4}{|c|}{ Resource Use Proportions } \\
\hline $\begin{array}{c}\text { General Practitioner (GP) face-to-face consultation for lower } \\
\text { respiratory tract infection (LRTI) }\end{array}$ & 0.95 & Beta $(20,1)$ & Raw data [26] \\
\hline $\begin{array}{c}\text { GP face-to-face consultation for acute respiratory tract } \\
\text { infection (ARTI) }\end{array}$ & 0.99 & Beta $(77,1)$ & Raw data [26] \\
\hline $\begin{array}{l}\text { Independent Nurse Prescriber (INP) face-to-face consultations } \\
\text { for LRTI }\end{array}$ & 0.05 & Beta $(1,20)$ & Raw data [26] \\
\hline GP face-to-face consultation for ARTI & 0.01 & Beta $(1,77)$ & Raw data [26] \\
\hline Telephone triage ${ }^{5}$ & 0.01 & Beta $(1,77)$ & Raw data [26] \\
\hline \multicolumn{4}{|c|}{ Costs (per unit) } \\
\hline GP consultation (9.22 minutes) & $£ 38.00$ & Fixed & [39] \\
\hline INP consultation (15 minutes consultation with band 7 ) & $£ 13.25$ & Fixed & [39] \\
\hline Telephone triage GP led (per telephone call) & $£ 14.60$ & Fixed & [39] \\
\hline Telephone triage nurse led (per telephone call) & $£ 6.10$ & Fixed & [39] \\
\hline Point-of-care (POC) CRP testing (per test) & $£ 9.58$ & Fixed & Table 4 \\
\hline Amoxicillin capsules ( $500 \mathrm{mg}$ three times daily for 5 days) & $£ 0.91$ & Fixed & [40] \\
\hline Amoxicillin capsules ( $500 \mathrm{mg}$ three times daily for 7 days) & $£ 1.27$ & Fixed & {$[40]$} \\
\hline Clarithromycin tablets (500 mg twice daily for 7 days) & $£ 2.23$ & Fixed & {$[40]$} \\
\hline Dispensing rate for community pharmacists (per item) & $£ 1.62$ & Fixed & [41] \\
\hline Emergency ambulance ${ }^{3}$ (per adverse drug reaction) & $£ 236.00$ & Fixed & [43] \\
\hline Emergency medicine ${ }^{4}$ (per adverse drug reaction) & $£ 362.00$ & Fixed & [43] \\
\hline \multirow{2}{*}{\multicolumn{4}{|c|}{ Utility (EQ-5D-3L score) ${ }^{6}$}} \\
\hline & & & \\
\hline U.K. population norm age $45-54$ years & 0.8470 & $\begin{array}{l}\text { 1-Gamma }(1.0000, \\
0.0015)\end{array}$ & [44] \\
\hline LRTI & 0.6750 & $\begin{array}{l}\text { 1-Gamma }(1.0000, \\
0.0033)\end{array}$ & [45] \\
\hline Upper respiratory tract infection (URTI). & 0.7970 & $\begin{array}{l}\text { 1-Gamma }(1.0000, \\
0.0020)\end{array}$ & {$[44,46,47]$} \\
\hline Anaphylaxis (adverse drug reaction) weight & 0.5 & Fixed & [47] \\
\hline Symptom Duration (days) & Median & & \\
\hline Patient reported time to full recovery: LRTI CRP & 15.5 & Beta $(2.8,5.5)$ & [18] \\
\hline Patient reported time to full recovery: LRTI Standard care & 20 & Beta $(4.4,4.5)$ & [18] \\
\hline Patient reported time to full recovery: URTI CRP & 14 & Beta $(2.3,6.2)$ & [18] \\
\hline Patient reported time to full recovery: URTI Standard care & 14 & Beta $(2.0,7.0)$ & [18] \\
\hline
\end{tabular}

${ }^{1}$ Distribution used in probabilistic sensitivity analysis ${ }^{2}$ Standard care for symptoms of ARTI for $>12$ hours where the antibiotic decision is unclear. ${ }^{3}$ National average unit cost for Ambulance ASSO2 See and treat and convey. ${ }^{4}$ National average unit cost for VB01Z Emergency Medicine, Any Investigation with Category 5 Treatment. ${ }^{5}$ Telephone triage lead ratio assumed to be equal to face-to-face ratio in the LRTI according to protocol model. ${ }^{6}$ Utilities for 365 days have been adjusted in the 28-day model. 
Table 4. Cost of point-of-care (POC) C-reactive protein (CRP) testing according to the CRP POC Testing Guidelines for Wales

\begin{tabular}{|c|c|c|c|c|}
\hline Item & Cost $(\ell)$ & $n$ & $£$ Per Test & References / Assumptions \\
\hline \multicolumn{5}{|c|}{ Resource Use } \\
\hline Number of tests per GP practice & - & 376 & - & $\begin{array}{l}\text { Projected from Hughes (2016) [26] } \\
\text { assuming constant rate of uptake }\end{array}$ \\
\hline Estimated life of the CRP Analyser (years) & - & 5 & - & Manufacturer quote (Alere) \\
\hline \multicolumn{5}{|c|}{ Fixed Costs } \\
\hline Afinion CRP analyser & 1500.00 & - & - & $\begin{array}{l}\text { Alere Afinion AS100 analyser (Alere; } \\
\text { MA, United States) }\end{array}$ \\
\hline Connectivity & 120.00 & - & - & $\begin{array}{l}\text { Betsi Cadwaladr University Health } \\
\text { Board (BCUHB) estimate }\end{array}$ \\
\hline Printer & 250.00 & - & - & Equal life to analyser \\
\hline Scanner & 125.00 & - & - & Equal life to analyser \\
\hline Total analyser set-up cost & 1995.00 & - & 1.06 & $\begin{array}{l}\text { Calculated using machine life and } \\
\text { number of tests per year }\end{array}$ \\
\hline \multicolumn{5}{|c|}{ Annual Costs } \\
\hline Associated connectivity cost & 20.00 & - & 0.05 & BCUHB estimate \\
\hline Internal quality control (IQC) & 136.00 & - & 0.36 & Guidelines for Wales [48] \\
\hline \multicolumn{5}{|l|}{ External quality assurance (EQA): Wales } \\
\hline $\begin{array}{l}\text { External Quality Assessment Service } \\
\text { (WEQAS) }\end{array}$ & 240.00 & - & 0.64 & Guidelines for Wales [48] \\
\hline $\begin{array}{l}\text { Laboratory support } \\
\text { (including travel, training, competency, } \\
\text { clinical interpretation, quality, and } \\
\text { troubleshooting support) }\end{array}$ & 468.92 & - & 1.25 & $\begin{array}{l}\text { BCUHB estimate based on mid-point } \\
\text { of AFC scale } 2017 \text { at each band and } \\
28.1 \% \text { on costs }\end{array}$ \\
\hline Maintenance cost (annual after 3-years) & 280 & - & 0.30 & 3-year warrantee \\
\hline Total annual support costs & $£ 976.92$ & - & 2.60 & \\
\hline \multicolumn{5}{|c|}{ Variable costs } \\
\hline Cartridge/reagent (per test) & - & - & 3.50 & \\
\hline Health care assistant (HCA) time & - & - & 2.42 & Band 4 for 5 minutes [39] \\
\hline Total variable costs & - & - & $£ 5.92$ & \\
\hline \multicolumn{5}{|c|}{ Total cost } \\
\hline Total cost per test & - & - & $£ 9.58$ & \\
\hline
\end{tabular}

\subsubsection{Health State Utilities}

Health state utilities were estimated for presenting complaint (Table 3). The utility associated with LRTI was the mean EuroQol EQ-5D-3L value at baseline for patients in Wales $(n=181)$ participating in an observational study of the management of patients with acute cough and LRTI in primary care $[1,45]$. For URTI, the decrement used in the NICE Clinical Guideline on antibiotic prescribing for respiratory tract infections [46,47], was applied to the U.K. age-specific population norm [44]. The utility of each RTI was assumed constant for the duration of symptoms [18], after which patients returned to the UK age-specific population norm [44]. Duration of symptoms associated with LRTI and URTI was the length of time from index consultation to patient-reported full recovery, from a study of patients with LRTI and rhinosinusitis [18]. Quality-adjusted life-years (QALYs) were then calculated for the 28-day time horizon of the model.

The model used price year 2016-17 for all costs. Discounting was not required due to short time horizon of the model.

\subsection{Analysis}

\subsubsection{Cost Per QALY}

The primary analysis for POC CRP testing for adults with symptoms of ARTI for $>12$ hours, versus, immediate antibiotic prescription, resulted in the calculation of the incremental cost-effectiveness ratio (ICER), as follows:

$$
I C E R=\frac{\operatorname{COST}_{\text {with test }}-\operatorname{COST}_{\text {standard care:no test }}}{\text { OUTCOME } E_{\text {with test }}-\text { OUTCOME } E_{\text {standard care:no test }}}
$$




\subsubsection{Cost-Effectiveness Analysis}

A secondary, cost-effectiveness of POC CRP testing considered the cost per antibiotic prescription avoided. The ICER was calculated as the incremental cost divided by the total number of prescriptions avoided ( $N$ Prescriptions with test, $N$ Prescriptions standard care with no test).

\subsubsection{Base-Case Analysis}

The care pathways in the base-case analysis allowed for deviation from the NICE guideline [11] by including all adult patients (including upper RTI) and reflecting the real world use of CRP testing. This used observational data to reflect actual clinical practice [26] which exhibits variable compliance with clinical and prescribing guidelines.

\subsubsection{Sensitivity Analyses}

A threshold analysis was conducted to establish the cost and throughput of testing at which the ICER met the NICE cost-effectiveness threshold of $£ 20,000$ per QALY [28]. A one-way sensitivity analysis was conducted on the probability that patients are seen by GP or INP at index and re-consultation. Probabilistic sensitivity analysis was also performed, using Monte Carlo simulation with 10,000 replications sampled from the distributions presented in Table 3. A CEAC was constructed to illustrate the probability of testing being cost-effective at given thresholds of cost-effectiveness [49].

\subsubsection{Scenario Analyses}

The NICE guidance advises that POC CRP testing should only be used for patients presenting with symptoms of LTRI for $>12$ hours, where the antibiotic decision is unclear. A scenario analysis was therefore conducted, assuming that all patients are treated according to the NICE (2014) guideline [11], and that if antibiotics were required, they were prescribed amoxicillin $500 \mathrm{mg}$ three times daily for 5 days (BCUHB Adult Antimicrobial Guide). The model structure is displayed in Figure 4.

Alternative modelled scenarios considered: (1) the possibility that patients would re-consult in standard care at the same rate as following POC CPR testing, irrespective of antibiotic outcome; (2) the impact of inappropriate prescribing on antibiotic resistance, based on costs extracted from Oppong et al., (2016) [27]; (3) antibiotics being dispensed by doctors rather than by community pharmacists, as might happen in more rural settings, and using local rates (personal communication); (4) the impact of hospitalizations related to ARTI on the cost-effectiveness of testing, based on published probabilities for CRP (0.009) and standard care (0.003) [11]; (5) the probability of reduced antibiotic prescribing in standard care (to 53\%) [11]; and (6) the prescribing of 5 days' supply of amoxicillin for ARTI (as per guideline); and (7) machine-life extended to 10-years. All parameter values used in the scenario analyses are detailed in table 5. The three estimates for the cost of antibiotic resistance were based on the annual cost of resistance in the United States (U.S.) ( $\$ 55$ billion) [50], the cost of multidrug resistance in the European Union (EU) (1.5 billion euro) [51], and the cost of global resistance over a 35-year period (\$2.8 trillion annually) [8]. Oppong and colleagues [27] estimated the cost per prescription in each scenario by calculating the cost of annual cost of resistance, divided by the annual number of prescriptions in each region-assuming antibiotic prescribing is the main cause of resistance. In the current analysis, estimates were converted into pounds sterling and then inflated to price year 2016-2017. 


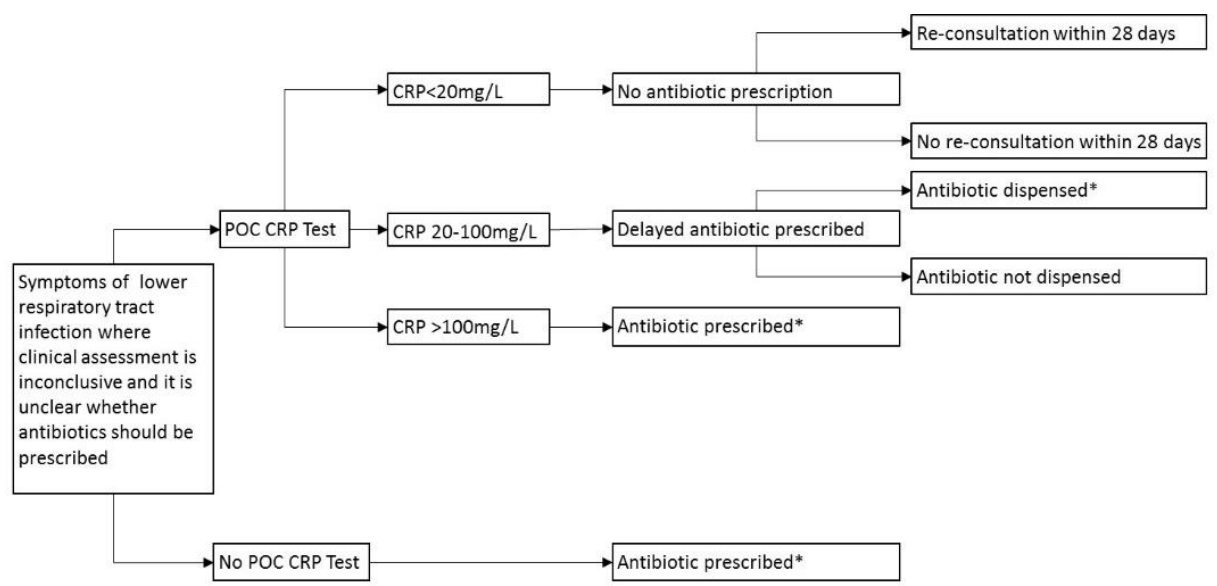

Figure 4. Decision tree for POC CRP testing adhering to guidelines, LRTI only. POC: Point-of-care; CRP: C-reactive protein; * Amoxicillin $500 \mathrm{mg}$ three times daily for 5 days.

Table 5. Model parameters for sensitivity analysis.

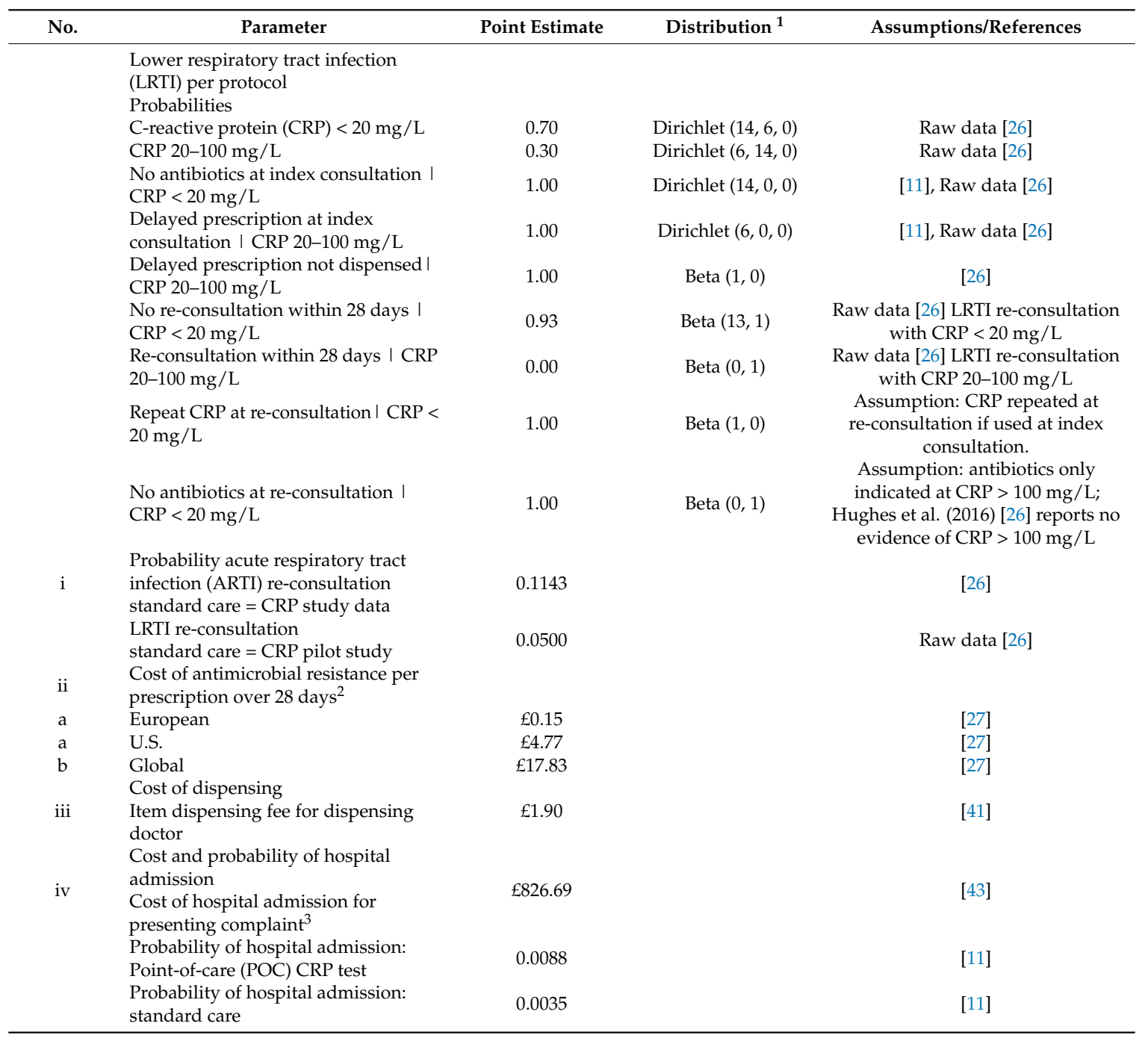


Table 5. Cont.

\begin{tabular}{|c|c|c|c|c|}
\hline No. & Parameter & Point Estimate & Distribution $^{1}$ & Assumptions/References \\
\hline $\mathrm{v}$ & $\begin{array}{l}\text { Probability of antibiotic use in } \\
\text { standard care }\end{array}$ & & & \\
\hline \multirow{3}{*}{ vi } & Antibiotic prescribing: standard care & 0.53 & & [11] \\
\hline & $\begin{array}{l}\text { Amoxicillin capsules: } 500 \mathrm{mg} \text { three } \\
\text { times daily for } 5 \text { days }\end{array}$ & $£ 0.91$ & & {$[40]$} \\
\hline & $\begin{array}{l}\text { Amoxicillin capsules: } 500 \mathrm{mg} \text { three } \\
\text { times daily for } 7 \text { days }\end{array}$ & $£ 1.27$ & & [40] \\
\hline
\end{tabular}

All analyses were performed in Microsoft Excel 2010 (Microsoft Corp., Redmond, WA, USA) and the study is reported according to the Consolidated Health Economic Evaluation Reporting Standards [52] [Appendix A].

\section{Conclusions}

POC CRP testing for adults where the antibiotic decision is unclear, is borderline cost-effective, however the results are favourable when restricted to patients with LRTI symptoms only adhering to protocol. Modelling pragmatic use of testing, reflective of practice, using observed data that deviated from protocols for both CRP-guided prescribing, and the length of prescription thereafter; illustrated the potential for variation in cost-effectiveness in clinical practice. POC testing for patients with upper respiratory tract infection is less likely to be cost-effective and comes with a higher opportunity cost for alternative use of NHS resources. The results of this economic evaluation are subject to considerable uncertainty, and therefore further empirical research is necessary.

Author Contributions: Conceptualization, E.A.F.H, S.D.H., A.H., N.C., and D.A.H.; methodology, E.A.F.H., D.A.H.; software, E.A.F.H.; validation, E.A.F.H. and D.A.H.; formal analysis, E.A.F.H.; investigation, E.A.F.H., S.D.H., and A.H.; resources, n/a; data curation, E.A.F.H., A.H., and S.A.F.H.; writing-original draft, E.A.F.H.; writing-review and editing, E.A.F.H., S.D.H., A.H., N.C., and D.A.H.; visualization, E.A.F.H; supervision, D.A.H.; project administration, E.A.F.H.; funding acquisition, E.A.F.H., S.D.H., A.H., N.C., and D.A.H.

Funding: This research was funded by Betsi Cadwaladr University Health Board (BCUHB), Pathway to Portfolio R\&D funding stream.

Acknowledgments: The authors acknowledge the contributions of Catrin Plumpton, CHEME, Bangor University; staff at Betsi Cadwaladr University Health Board (BCUHB) involved in the delivery of POC testing-Louise Gwyn, Avril M Wayte, Claire Clarke, Marge Everall, Sarah Jones; and the Amlwch Health Centre-GPs, nurses, the practice manager, and staff.

Conflicts of Interest: The authors declare no conflict of interest. The funders had no role in the design of the study; in the collection, analyses, or interpretation of data; in the writing of the manuscript, or in the decision to publish the results. 


\section{Appendix A.}

Table A1. CHEERS checklist-Items to include when reporting economic evaluations of health interventions.

\begin{tabular}{|c|c|c|c|}
\hline Section/Item & Item No & Recommendation & $\begin{array}{l}\text { Reported on Page } \\
\text { No/line No }\end{array}$ \\
\hline \multicolumn{4}{|c|}{ Title and abstract } \\
\hline Title & 1 & $\begin{array}{l}\text { Identify the study as an economic evaluation or } \\
\text { use more specific terms such as } \\
\text { "cost-effectiveness analysis", and describe the } \\
\text { interventions compared. }\end{array}$ & Lines 2-4 \\
\hline Abstract & 2 & $\begin{array}{l}\text { Provide a structured summary of objectives, } \\
\text { perspective, setting, methods (including study } \\
\text { design and inputs), results (including base case } \\
\text { and uncertainty analyses), and conclusions. }\end{array}$ & Lines 18-32 \\
\hline \multicolumn{4}{|c|}{ Introduction } \\
\hline \multirow{2}{*}{ Background and objectives } & \multirow{2}{*}{3} & $\begin{array}{l}\text { Provide an explicit statement of the broader } \\
\text { context for the study. }\end{array}$ & Lines 38-56 \\
\hline & & $\begin{array}{l}\text { Present the study question and its relevance for } \\
\text { health policy or practice decisions. }\end{array}$ & Lines 74-83 \\
\hline \multicolumn{4}{|c|}{ Methods } \\
\hline Target population and subgroups & 4 & $\begin{array}{l}\text { Describe characteristics of the base case } \\
\text { population and subgroups analysed, including } \\
\text { why they were chosen. }\end{array}$ & $\begin{array}{l}\text { Lines } 273-276 \\
\text { Lines } 315-320\end{array}$ \\
\hline Setting and location & 5 & $\begin{array}{l}\text { State relevant aspects of the system(s) in which } \\
\text { the decision }(\mathrm{s}) \text { need(s) to be made. }\end{array}$ & $\begin{array}{c}\text { Lines } 58-73 \\
\text { Lines } 273-275 \\
\text { Lines } 302-307\end{array}$ \\
\hline Study perspective & 6 & $\begin{array}{l}\text { Describe the perspective of the study and relate } \\
\text { this to the costs being evaluated. }\end{array}$ & Line 275 \\
\hline Comparators & 7 & $\begin{array}{l}\text { Describe the interventions or strategies being } \\
\text { compared and state why they were chosen. }\end{array}$ & Lines 282-287 \\
\hline Time horizon & 8 & $\begin{array}{l}\text { State the time horizon(s) over which costs and } \\
\text { consequences are being evaluated and say why } \\
\text { appropriate. }\end{array}$ & Line 280 \\
\hline Discount rate & 9 & $\begin{array}{l}\text { Report the choice of discount rate(s) used for } \\
\text { costs and outcomes and say why appropriate. }\end{array}$ & Line 384 \\
\hline Choice of health outcomes & 10 & $\begin{array}{l}\text { Describe what outcomes were used as the } \\
\text { measure(s) of benefit in the evaluation and their } \\
\text { relevance for the type of analysis performed. }\end{array}$ & Line 373 \\
\hline \multirow[t]{2}{*}{ Measurement of effectiveness } & $11 \mathrm{a}$ & $\begin{array}{l}\text { Single study-based estimates: Describe fully the } \\
\text { design features of the single effectiveness study } \\
\text { and why the single study was a sufficient source } \\
\text { of clinical effectiveness data. }\end{array}$ & \multirow[t]{2}{*}{$\begin{array}{l}\text { Prescriptions avoided: } \\
\text { Lines 301-313 } \\
\text { Utility: Lines 373-382 }\end{array}$} \\
\hline & $11 b$ & $\begin{array}{l}\text { Synthesis-based estimates: Describe fully the } \\
\text { methods used for identification of included } \\
\text { studies and synthesis of clinical effectiveness } \\
\text { data. }\end{array}$ & \\
\hline $\begin{array}{l}\text { Measurement and valuation of } \\
\text { preference based outcomes }\end{array}$ & 12 & $\begin{array}{l}\text { If applicable, describe the population and } \\
\text { methods used to elicit preferences for outcomes. }\end{array}$ & Lines 373-382 \\
\hline \multirow[t]{2}{*}{ Estimating resources and costs } & $13 a$ & $\begin{array}{l}\text { Single study-based economic evaluation: } \\
\text { Describe approaches used to estimate resource } \\
\text { use associated with the alternative interventions. } \\
\text { Describe primary or secondary research methods } \\
\text { for valuing each resource item in terms of its unit } \\
\text { cost. Describe any adjustments made to } \\
\text { approximate to opportunity costs. }\end{array}$ & \\
\hline & $13 b$ & $\begin{array}{l}\text { Model-based economic evaluation: Describe } \\
\text { approaches and data sources used to estimate } \\
\text { resource use associated with model health states. } \\
\text { Describe primary or secondary research methods } \\
\text { for valuing each resource item in terms of its unit } \\
\text { cost. Describe any adjustments made to } \\
\text { approximate to opportunity costs. }\end{array}$ & $\begin{array}{l}\text { Lines } 328-385 \\
\quad 3 \& 4\end{array}$ \\
\hline
\end{tabular}


Table A1. Cont.

\begin{tabular}{|c|c|c|c|}
\hline Section/Item & Item No & Recommendation & $\begin{array}{l}\text { Reported on Page } \\
\text { No/line No }\end{array}$ \\
\hline \multicolumn{4}{|c|}{ Methods } \\
\hline Currency, price date, and conversion & 14 & $\begin{array}{l}\text { Report the dates of the estimated resource } \\
\text { quantities and unit costs. Describe methods for } \\
\text { adjusting estimated unit costs to the year of } \\
\text { reported costs if necessary. Describe methods for } \\
\text { converting costs into a common currency base } \\
\text { and the exchange rate. }\end{array}$ & Lines 328-385 \\
\hline Choice of model & 15 & $\begin{array}{l}\text { Describe and give reasons for the specific type of } \\
\text { decision-analytical model used. Providing a } \\
\text { figure to show model structure is strongly } \\
\text { recommended. }\end{array}$ & $\begin{array}{l}\text { Lines } 280-293 \\
\quad 3 \& 4\end{array}$ \\
\hline Assumptions & 16 & $\begin{array}{l}\text { Describe all structural or other assumptions } \\
\text { underpinning the decision-analytical model. }\end{array}$ & Lines 280-385 \\
\hline Analytical methods & 17 & $\begin{array}{l}\text { Describe all analytical methods supporting the } \\
\text { evaluation. This could include methods for } \\
\text { dealing with skewed, missing, or censored data; } \\
\text { extrapolation methods; methods for pooling data; } \\
\text { approaches to validate or make adjustments } \\
\text { (such as half cycle corrections) to a model; and } \\
\text { methods for handling population heterogeneity } \\
\text { and uncertainty. }\end{array}$ & Lines $413-445$ \\
\hline \multicolumn{4}{|c|}{ Results } \\
\hline Study parameters & 18 & $\begin{array}{l}\text { Report the values, ranges, references, and, if } \\
\text { used, probability distributions for all parameters. } \\
\text { Report reasons or sources for distributions used } \\
\text { to represent uncertainty where appropriate. } \\
\text { Providing a table to show the input values is } \\
\text { strongly recommended. }\end{array}$ & Table 3 \\
\hline Incremental costs and outcomes & 19 & $\begin{array}{l}\text { For each intervention, report mean values for the } \\
\text { main categories of estimated costs and outcomes } \\
\text { of interest, as well as mean differences between } \\
\text { the comparator groups. If applicable, report } \\
\text { incremental cost-effectiveness ratios. }\end{array}$ & Table 1 \\
\hline \multirow[t]{2}{*}{ Characterising uncertainty } & $20 \mathrm{a}$ & $\begin{array}{l}\text { Single study-based economic evaluation:Describe } \\
\text { the effects of sampling uncertainty for the } \\
\text { estimated incremental cost and incremental } \\
\text { effectiveness parameters, together with the } \\
\text { impact of methodological assumptions (such as } \\
\text { discount rate, study perspective). }\end{array}$ & \\
\hline & $20 \mathrm{~b}$ & $\begin{array}{l}\text { Model-based economic evaluation: Describe the } \\
\text { effects on the results of uncertainty for all input } \\
\text { parameters, and uncertainty related to the } \\
\text { structure of the model and assumptions. }\end{array}$ & $\begin{array}{l}\text { Lines } 114-128 \\
\text { Lines } 138-141\end{array}$ \\
\hline Characterising heterogeneity & 21 & $\begin{array}{l}\text { If applicable, report differences in costs, } \\
\text { outcomes, or cost-effectiveness that can be } \\
\text { explained by variations between subgroups of } \\
\text { patients with different baseline characteristics or } \\
\text { other observed variability in effects that are not } \\
\text { reducible by more information. }\end{array}$ & $\begin{array}{l}\text { Lines } 129-151 \\
\text { Tables } 1 \text { and } 2 \\
\text { Figures } 1 \text { and } 2\end{array}$ \\
\hline \multicolumn{4}{|c|}{ Discussion } \\
\hline $\begin{array}{l}\text { Study findings, limitations, } \\
\text { generalisability, and current } \\
\text { knowledge }\end{array}$ & 22 & $\begin{array}{l}\text { Summarise key study findings and describe how } \\
\text { they support the conclusions reached. Discuss } \\
\text { limitations and the generalisability of the } \\
\text { findings and how the findings fit with current } \\
\text { knowledge. }\end{array}$ & Lines 154-169 \\
\hline \multicolumn{4}{|c|}{ Other } \\
\hline Source of funding & 23 & $\begin{array}{l}\text { Describe how the study was funded and the role } \\
\text { of the funder in the identification, design, } \\
\text { conduct, and reporting of the analysis. Describe } \\
\text { other non-monetary sources of support. }\end{array}$ & Line 461 \\
\hline Conflicts of interest & 24 & $\begin{array}{l}\text { Describe any potential for conflict of interest of } \\
\text { study contributors in accordance with journal } \\
\text { policy. In the absence of a journal policy, we } \\
\text { recommend authors comply with International } \\
\text { Committee of Medical Journal Editors } \\
\text { recommendations. }\end{array}$ & Line 467 \\
\hline
\end{tabular}

For consistency, the CHEERS statement checklist format is based on the format of the CONSORT statement checklist. 


\section{References}

1. Butler, C.C.; Hood, K.; Verheij, T.; Little, P.; Melbye, H.; Nuttall, J.; Kelly, M.J.; Mölstad, S.; Godycki-Cwirko, M.; Almirall, J.; et al. Variation in antibiotic prescribing and its impact on recovery in patients with acute cough in primary care: Prospective study in 13 countries. BMJ 2009, 338, b2242. [CrossRef] [PubMed]

2. Currie, C.J.; Berni, E.; Jenkins-Jones, S.; Poole, C.D.; Ouwens, M.; Driessen, S.; de Voogd, H.; Butler, C.C.; Morgan, C.L. Antibiotic treatment failure in four common infections in UK primary care 1991-2012: Longitudinal analysis. BMJ 2014, 349, g5493. [CrossRef] [PubMed]

3. Llor, C.; Bjerrum, L. Antimicrobial resistance: Risk associated with antibiotic overuse and initiatives to reduce the problem. Ther. Adv. Drug Saf. 2014, 5, 229-241. [CrossRef] [PubMed]

4. Costelloe, C.; Metcalfe, C.; Lovering, A.; Mant, D.; Hay, A.D. Effect of antibiotic prescribing in primary care on antimicrobial resistance in individual patients: Systematic review and meta-analysis. BMJ 2010, 340, c2096. [CrossRef] [PubMed]

5. Bell, B.G.; Schellevis, F.; Stobberingh, E.; Goossens, H.; Pringle, M. A systematic review and meta-analysis of the effects of antibiotic consumption on antibiotic resistance. BMC Infect. Dis. 2014, 14, 13. [CrossRef] [PubMed]

6. Owens, R.C., Jr.; Donskey, C.J.; Gaynes, R.P.; Loo, V.G.; Muto, C.A. Antimicrobial-associated risk factors for Clostridium difficile infection. Clin. Infect. Dis. 2008, 46, S19-S31. [CrossRef] [PubMed]

7. WHO Patient Safety. The Evolving Threat of Antimicrobial Resistance: Options for Action; WHO: Geneva, Switzerland, 2012.

8. O'Neill, J. Tackling Drug-Resistant Infections Globally: Final Report and Recommendations. 2016. Available online: https:/ / amr-review.org/sites/default/files/160525_Final\%20paper_with\%20cover.pdf (accessed on 26 June 2018).

9. National Institute of Health and Care Excellence (NICE) Guidelines on Antimicrobial Stewardship. Quality Standard [QS121]. Published date: April 2016. Available online: https://www.nice.org.uk/guidance/qs121 (accessed on 13 March 2018).

10. Welsh Government. Together for Health. Tackling Antimicrobial Resistance and Improving Antibiotic Prescribing; Welsh Government: Cardiff, UK, 2015.

11. National Institute for Health and Care Excellence. CG191 Pneumonia in Adults: Diagnosis and Management. 2014. Available online: https:/ / www.nice.org.uk/guidance/cg191 (accessed on 23 September 2017).

12. Welsh Scientific Advisory Committee. Policy on the Management of Point of Care Testing, What, When and How? May 2017, WG31745. Digital ISBN 978-1-4734-9536-. Available online: https://gov.wales/docs/dhss/ publications/170918whc034en.pdf (accessed on 6 December 2018).

13. Huang, Y.; Chen, R.; Wu, T.; Wei, X.; Guo, A. Association between point-of-care CRP testing and antibiotic prescribing in respiratory tract infections: A systematic review and meta-analysis of primary care studies. Br. J. Gen. Pract. 2013, 63, e787-e794. [CrossRef]

14. Cooke, J.; Butler, C.; Hopstaken, R.; Dryden, M.S.; McNulty, C.; Hurding, S.; Moore, M.; Livermore, D.M. Narrative review of primary care point-of-care testing (POCT) and antibacterial use in respiratory tract infection (RTI). BMJ Open Respir. Res. 2015, 2, e000086. [CrossRef]

15. Andreeva, E.; Melbye, H. Usefulness of C-reactive protein testing in acute cough/respiratory tract infection: An open cluster-randomized clinical trial with C-reactive protein testing in the intervention group. BMC Fam. Pract. 2014, 15, 80. [CrossRef]

16. Little, P.; Stuart, B.; Francis, N.; Douglas, E.; Tonkin-Crine, S.; Anthierens, S.; Cals, J.W.; Melbye, H.; Santer, M.; Moore, M.; et al. Effects of internet-based training on antibiotic prescribing rates for acute respiratory-tract infections: A multinational, cluster, randomised, factorial, controlled trial. Lancet 2013, 382, 1175-1182. [CrossRef]

17. Bjerrum, L.; Gahrn-Hansen, B.; Munck, A.P. General practitioners who use CRP have a lower antibiotic prescribing rate to patients with sinusitis-Secondary publication. Ugeskr. Laeger. 2005, 167, 2775-2777.

18. Cals, J.W.; Schot, M.J.; de Jong, S.A.; Dinant, G.J.; Hopstaken, R.M. Point-of-care C-reactive protein testing and antibiotic prescribing for respiratory tract infections: A randomized controlled trial. Ann. Fam. Med. 2010, 8, 124-133. [CrossRef] 
19. Diederichsen, H.Z.; Skamling, M.; Diederichsen, A.; Grinsted, P.; Antonsen, S.; Petersen, P.H.; Munck, A.P.; Kragstrup, J. Randomised controlled trial of CRP rapid test as a guide to treatment of respiratory infections in general practice. Scand. J. Prim. Health Care 2000, 18, 39-43. [CrossRef] [PubMed]

20. Cals, J.W.; Ament, A.J.; Hood, K.; Butler, C.C.; Hopstaken, R.M.; Wassink, G.F.; Dinant, G.J. C-reactive protein point of care testing and physician communication skills training for lower respiratory tract infections in general practice: Economic evaluation of a cluster randomized trial. J. Eval. Clin. Pract. 2011, 17, 1059-1069. [CrossRef]

21. Dahler-Eriksen, B.S.; Lauritzen, T.; Lassen, J.F.; Lund, E.D.; Brandslund, I. Near patient test for C-reactive protein in general practice: Assessment of clinical, organizational and economic outcomes. Clin. Chem. 1999, 45, 478-485. [PubMed]

22. Hunter, R. Cost-effectiveness of point-of-care C-reactive protein tests for respiratory tract infection in primary care in England. Adv. Ther. 2015, 32, 69-85. [CrossRef]

23. Oppong, R.; Jit, M.; Smith, R.D.; Butler, C.C.; Melbye, H.; Mölstad, S.; Coast, J. Cost-effectiveness of point-of-care C-reactive protein testing to inform antibiotic prescribing decisions. Br. J. Gen. Pract. 2013, 63, e465-e471. [CrossRef]

24. National POCT Standards; ISO22870:2006; Royal College of Pathologists ISO: London, UK, 2006.

25. Smith, R.; Coast, J. The true cost of antimicrobial resistance. BMJ 2013, 346, f1493. [CrossRef] [PubMed]

26. Hughes, A.; Gwyn, L.; Harris, S.; Clark, C. Evaluating point-of-care C-reactive protein testing in a general practice. Clin. Pharm. 2016, 8, 309-318.

27. Oppong, R.; Smith, R.D.; Little, P.; Verheij, T.; Butler, C.C.; Goossens, H.; Coenen, S.; Moore, M.; Coast, J. Cost-effectiveness of amoxicillin for lower respiratory tract infections in primary care: An economic evaluation accounting for the cost of antimicrobial resistance. Br. J. Gen. Pract. 2016, 21, e633-e639. [CrossRef]

28. National Institute for Health and Care Excellence. Guide to the Methods of Technology Appraisal 2013. Available online: https:/ / www.nice.org.uk/process/pmg9/chapter/foreword (accessed on 12 March 2018).

29. Wilcox, M.H.; Ahir, H.; Coia, J.E.; Dodgson, A.; Hopkins, S.; Llewelyn, M.J.; Settle, C.; Mclain-Smith, S.; Marcella, S.W. Impact of recurrent Clostridium difficile infection: Hospitalization and patient quality of life. J. Antimicrob. Chemother. 2017, 72, 2647-2656. [CrossRef] [PubMed]

30. Bala, M.V.; Zarkin, G.A. Are QALYs an appropriate measure for valuing morbidity in acute diseases? Health Econ. 2000, 9, 177-180. [CrossRef]

31. Rothery, C.; Woods, B.; Schmitt, L.; Claxton, K.; Palmer, S.; Sculpher, M. Framework for value assessment of new antimicrobials. Policy Research Unit in Economic Evaluations of Health \& Care Interventions, York. September 2018. Available online: http:/ / www.eepru.org.uk/wp-content/uploads/2017/11/ eepru-reportamr-oct-2018-059.pdf (accessed on 19 November 2018).

32. House of Commons Health and Social Care Committee. Antimicrobial Resistance. Eleventh Report of Session 2017-2019. 22 October 2018 HC962. Available online: https://publications.parliament.uk/pa/ cm201719/cmselect/cmhealth/962/962.pdf (accessed on 19 November 2018).

33. Spurling, G.K.; Del Mar, C.B.; Dooley, L.; Foxlee, R.; Farley, R. Delayed Antibiotic Prescriptions for Respiratory Infections; The Cochrane Library: London, UK, 1 January 2017.

34. Saramago, P.; Manca, A.; Sutton, A.J. Deriving input parameters for cost-effectiveness modelling: Taxonomy of data types and approaches to their statistical synthesis. Value Health 2012, 15, 639-649. [CrossRef] [PubMed]

35. Adams, H.; Craine, N. Exploring Primary Care Antibiotic Prescribing; Version 1; Betsi Cadwaladr University Health Board (BCUHB): North Wales, UK, February 2017.

36. NHS Wales Shared Services. 'Primary Care Prescribing Catalogue'. Available online: http://prescribing. wales.nhs.uk/OnlineCatalogueV2/home/login (accessed on 4 September 2018).

37. Summary of Product Characteristics (SPC): Amoxicillin $500 \mathrm{mg}$ Capsules BP [04/08/2017]. Available online: https://www.medicines.org.uk/emc/medicine/25942\#UNDESIRABLE_EFFECTS (accessed on 21 September 2017).

38. Hobbs, R.; Bankhead, C.; Mukhtar, T.; Stevens, S.; Perera-Salazar, R.; Holt, T.; Salisbury, C. Clinical workload in UK primary care: A retrospective analysis of 100 million consultations in England, 2007-14. Lancet 2016, 387, 2323-2330. [CrossRef] 
39. PSSRU Unit Costs of Health and Social Care 2017. Available online: https://www.pssru.ac.uk/projectpages/unit-costs/unit-costs-2017/ (accessed on 23 June 2018).

40. British National Formulary (BNF). September 2017. Available online: https://bnf.nice.org.uk (accessed on 24 September 2017).

41. Holt, R. Personal Communication.

42. NHS Choices Anaphylaxis. Dated: 2 December 2016. Available online: http://www.nhs.uk/conditions/ Anaphylaxis/Pages/Introduction.aspx\#treatment (accessed on 24 September 2017).

43. Department of Health, NHS England and NHS Improvement. NHS Reference Costs 2016-2017. Department of Health and Social Care. 2017. Available online: https:/ /improvement.nhs.uk/resources/reference-costs / (accessed on 17 October 2018).

44. Janssen, B.; Szende, A. Population Norms for the EQ-5D. In Self-Reported Population Health: An International Perspective Based on EQ-5D; Szende, A., Janssen, B., Cabases, J., Eds.; Springer: Dordrecht, The Netherlands, 2014.

45. Oppong, R.; Kaambwa, B.; Nuttall, J.; Hood, K.; Smith, R.D.; Coast, J. The impact of using different tariffs to value EQ-5D health state descriptions: An example from a study of acute cough/lower respiratory tract infections in seven countries. Eur. J. Health Econ. 2013, 14, 197-209. [CrossRef] [PubMed]

46. Neuner, J.M.; Hamel, M.B.; Phillips, R.S.; Bona, K.; Aronson, M.D. Diagnosis and management of adults with pharyngitis: A cost-effectiveness analysis. Ann. Intern. Med. 2003, 139, 113-122. [CrossRef] [PubMed]

47. National Institute for Health and Care Excellence. CG69 Respiratory tract infections-Antibiotic prescribing. 2008. Available online: http:/ / www.nice.org.uk/guidance/cg69/ (accessed on 23 September 2017).

48. CRP POCT Guidelines for Wales. Using CRP Testing to Support Clinical Decisions in Primary Care. Available online: http:/ / www.gpone.wales.nhs.uk/sitesplus/documents / 1000/crp\%20poc\%20testing\% 20guidelines\%20for\%20wales.docx (accessed on 25 September 2017).

49. Fenwick, E.; Claxton, K.; Sculpher, M. Representing uncertainty: The role of cost-effectiveness acceptability curves. Health Econ. 2001, 10, 779-787. [CrossRef] [PubMed]

50. Centers for Disease Control and Prevention. Antimicrobial Resistance: No Action Today, no Cure Tomorrow. World Health Day: Media Fact Sheet. 7 April 2011. Available online: http:/ /www.cdc.gov/media/releases/ 2011/f0407_antimicrobialresistance.pdf (accessed on 19 November 2018).

51. European Centre for Disease Prevention and Control, European Medicines Agency. The bacterial challenge: Time to React. Joint Technical Report. Stockholm: ECDPC. 2009. Available online: https:/ / ecdc.europa.eu/sites/portal/ files/media/en/publications/Publications/0909_TER_The_Bacterial_Challenge_Time_to_React.pdf (accessed on 19 November 2018).

52. Husereau, D.; Drummond, M.; Petrou, S.; ISPOR Health Economic Evaluation Publication Guidelines-CHEERS Good Reporting Practices Task Force. Consolidated Health Economic Evaluation Reporting Standards (CHEERS)-explanation and elaboration: A report of the ISPOR Health Economic Evaluation Publication Guidelines Good Reporting Practices Task Force. Value Health 2013, 16, 231-250.

(C) 2018 by the authors. Licensee MDPI, Basel, Switzerland. This article is an open access article distributed under the terms and conditions of the Creative Commons Attribution (CC BY) license (http://creativecommons.org/licenses/by/4.0/). 